\title{
FÓRUM
}

Submetido em 13.11.2013. Aprovado em 29.05.2014

Avaliado pelo sistema double blind review. Editores Científicos: Maria Tereza Saraiva de Souza, Orlando Cattini Junior e José Carlos Barbieri

http://dx.doi.org/10.1590/So034-759020140503

\section{A PRÁTICA DA GESTÃO DE OPERAÇÕES NAS ORGANIZAÇÕES}

\author{
The practice of Operations Management in organizations \\ La práctica de la Gestión de Operaciones en las organizaciones
}

\section{RESUMO}

Este artigo procurou identificar as temáticas da Gestão de Operações que são atualmente valorizadas por empresas montadoras do setor automotivo na criação, utilização e disseminação de novos conceitos produtivos. Para isso, foi realizada uma análise de conteúdo dos documentos que direcionam os sistemas de produção adotados por quatro grandes montadoras com plantas na cidade de Curitiba. Constatou-se que seis temas se destacam: gestão da qualidade; sistema de produção enxuta; gerenciamento de recursos humanos em operações; gerenciamento da produção e processos; projeto, mensuração e melhoria do trabalho; e mensuração do desempenho e produtividade.

PALAVRAS-CHAVE | Gestão de Operações, prática em operações, sistemas produtivos, processos produtivos, indústria automotiva.

\section{ABSTRACT}

This paper sought to identify the themes of Operations Management that are currently valued by automotive manufacturers in the creation, use and dissemination of new production concepts. For such, it conducted a content analysis of documents that drive the production systems adopted by the four major manufacturers, with plants in the city of Curitiba. Six themes were seen to stand out: quality management; lean production system; human resource management in operations; production and process management; design, measurement and improvement of work; and measurement of performance and productivity.

KEY WORDS I Operations Management, operations practices, production systems, productive processes, automotive industry.

\section{JURANDIR PEINADO}

jurandirpeinado@gmail.com Professor da Universidade Positivo Curitiba - PR, Brasil

\section{ALEXANDRE REIS GRAEML}

alexandre.graeml@gmail.com Professor do Programa de Pósgraduação em Computação Aplicada, Universidade Tecnológica Federal do Paraná, Curitiba, PR - Brasil

\section{RESUMEN}

Este artículo busca identificar las temáticas de la Gestión de Operaciones actualmente valorizadas por empresas montadoras del sector automotriz en la creación, utilización y difusión de nuevos conceptos productivos. Para esto, fue realizado un análisis de contenido de los documentos que dirigen los sistemas de producción adoptados por cuatro grandes montadoras con plantas en la ciudad de Curitiba. Se constató que hay seis temas destacados: gestión de calidad; sistema de producción ajustada; gestión de recursos humanos en operaciones; gestión de producción y procesos; proyecto, medición y mejora del trabajo y medición del desempeño y productividad.

PALABRAS CLAVE / Gestión de Operaciones, práctica en operaciones, sistemas productivos, procesos productivos, industria automotriz. 


\section{INTRODUÇÃO}

Este artigo procurou identificar as temáticas da Gestão de Operações que, na prática atual, são valorizadas pelas empresas industriais consideradas mais expressivas na criação, utilização e disseminação de novos conceitos produtivos. Para isso, foram estudadas as fontes documentais representadas pelos sistemas de produção adotados por quatro grandes montadoras do ramo automotivo. Procurou-se identificar os temas e conceitos da Gestão de Operações contidos nos documentos de orientação dos sistemas de produção dessas montadoras, na tentativa de compreender como elas percebem a sua relevância para a prática empresarial. Assume-se aqui o pressuposto de que os temas e conceitos de Gestão de Operações mencionados nos documentos pesquisados dessas empresas são por elas considerados relevantes e merecedores da atenção dos seus funcionários envolvidos na operação produtiva.

O desenvolvimento da pesquisa justifica-se, do ponto de vista prático, pela possibilidade de divulgação dos temas em Gestão de Operações mais valorizados pelas grandes montadoras, para pesquisadores interessados na área e professores dos cursos de Administração, como forma de alinhar seus esforços às necessidades de quem utiliza os conhecimentos produzidos $\mathrm{e}$ disseminados nas universidades na sua prática cotidiana em ambiente empresarial. A partir de uma perspectiva teórica, a realização da pesquisa justifica-se, ainda, pela constatação da existência de poucos trabalhos de âmbito nacional ou internacional que tratem da questão e contribuam para um melhor alinhamento entre pesquisa, ensino e prática de Gestão de Operações.

Nas seções seguintes, apresenta-se um levantamento das mais recentes pesquisas científicas sobre práticas de Gestão de Operações em empresas montadoras de veículos e/ou ligadas ao ramo automotivo com planta no território nacional. Depois, a metodologia utilizada na coleta e na análise dos dados é apresentada e discutida. Encerra-se o trabalho com algumas considerações finais, que incluem possíveis encaminhamentos para futuros estudos e as limitações da pesquisa ora empreendida.

\section{PESQUISAS CIENTÍFICAS SOBRE PRÁTICAS DE GESTÃO DE OPERAÇÕES EM EMPRESAS DO SETOR AUTOMOTIVO NO BRASIL}

Entre os diversos temas da Gestão de Operações, o gerenciamento da cadeia de suprimento aparece de modo recorrente na literatura da área. Abordando o assunto, Vanalle e Salles (2011) estudaram as relações entre montadoras e fornecedores do parque industrial automobilístico brasileiro, por meio entrevistas com profissionais das áreas de produção, logística e suprimentos, desenvolvimento de produto e processo, compras e recursos humanos de 14 empresas fornecedoras de montadoras. Os autores concluíram que as relações entre cliente e fornecedor seguem um modelo associativo, com relações contratuais de longo prazo e grande interdependência, mas o preço ainda é utilizado como o principal critério ganhador de pedido na seleção de fornecedores pelas montadoras. Guarnieri e Hatakeyama (2010) estudaram o nível de formalização na logística de suprimentos em amostra composta de 23 montadoras e 50 fornecedores provenientes da indústria automotiva brasileira. Os assuntos abordados no estudo foram: administração de estoques, adoção da filosofia just-in-time, adoção da curva $A B C$ de estoques e coleta milk run, transportes no processo de suprimentos e operadores logísticos e TI na cadeia de suprimentos (ERP). Os autores constataram que as práticas adotadas pelas montadoras e pelos seus fornecedores são convergentes, embora, nas montadoras, essas práticas estejam mais desenvolvidas. Pires e Sacomano (2010) realizaram uma pesquisa envolvendo diferentes configurações na estrutura de relacionamento entre uma montadora de automóveis e quatro de seus fornecedores em uma cadeia de suprimentos da indústria automobilística. Os temas utilizados para a análise proposta foram: tipos de relacionamentos, processos logísticos, planejamento de produtos, gestão da produção e medição de desempenho. Os resultados da pesquisa indicam que a configuração da cadeia é fator determinante na forma como se conduz o relacionamento da montadora com seus fornecedores. Vieira, Pasa, Borsa, Milan e Pandolfo (2011) apresentam um estudo de caso sobre as formas de gestão na movimentação de materiais em uma indústria do ramo automotivo nacional. 0 estudo envolveu a associação entre a movimentação de materiais e o fluxo de produção, comprovando o relacionamento direto entre três variáveis: tempo de trânsito, uso dos recursos e nível de serviço.

A gestão de projetos e o desenvolvimento de novos produtos constituem também temas da Gestão de Operações que aparecem com frequência na literatura. A respeito desse assunto, Rodrigues, Carnevalli e Miguel (2012) investigaram o emprego da modularidade no projeto de produto e na produção, entre uma montadora de veículos comerciais e duas empresas fornecedoras de motores. Os autores constataram que o conceito de modularidade pode ser aplicado ao processo produtivo sem que necessariamente o produto tenha sido concebido em módulos.

Silva, Mello, Siqueira, Godoy e Salgado (2010) analisaram a incorporação do gerenciamento de riscos no processo de desenvolvimento de produtos nas empresas de autopeças, com base no Advanced Product Quality Planning (APQP). Os fatores 
que se destacaram para se obterem melhores resultados foram: a formação da equipe; a discussão coletiva dos prazos, tendo como resultado o comprometimento; o papel do gerente do projeto, propiciando o feedback entre os participantes; e a existência de evidências objetivas do apoio da alta administração. Em um estudo multicaso envolvendo quatro montadoras de veículos, Prieto e Miguel (2011) analisaram as implicações da transferência de atividades no desenvolvimento de produto devido à adoção da estratégia modular.

Melo e Pereira (2012) investigaram as especificidades do gerenciamento de projetos de automação na indústria automobilística, desenvolvendo e testando um modelo conceitual, de modo a inserir a aprendizagem organizacional na gestão de projetos proposta pela metodologia tradicional do Project Management Institute (PMI). Os autores concluem que a aplicação da aprendizagem organizacional no contexto dos processos de gerenciamento de projetos permite que as empresas usufruam benefícios maiores que os experimentados na aplicação única de uma metodologia de gerenciamento de projetos.

Práticas ligadas ao gerenciamento de recursos humanos também fazem parte dos temas ligados à Gestão de Operações. Em um estudo multicaso envolvendo três empresas do ramo automotivo, Gonzalez e Martins (2011) confirmam que a simples implantação de programas e ferramentas para resolução de problemas não é suficiente, é preciso que as organizações estimulem a aprendizagem e a cooperação entre seus funcionários por meio do desenvolvimento dos recursos humanos para que tais iniciativas de melhoria sejam, de fato, contínuas. Nessa mesma linha, por meio de uma survey com 75 empresas do setor automotivo, Jabbour, Freitas, Teixeira e Jabbour (2012) revelam que, realmente, a gestão de recursos humanos está relacionada com o desempenho operacional das empresas pesquisadas. Em uma pesquisa realizada na linha de montagem de uma tradicional montadora de automóveis, Muniz, Faria e Sá (2011) analisam a tríade organizacional formada por produção, trabalho e conhecimento, do ponto de vista de trabalhadores de chão de fábrica (blue collars). Os autores concluem que os principais fatores para a criação de ambiente favorável à difusão de conhecimento são: (1) compreensão dos objetivos da gestão e dos trabalhadores, (2) definição clara dos papéis e responsabilidades do pessoal envolvido em atividades produtivas, (3) boa comunicação entre os envolvidos com a produção, (4) oportunidades para formação profissional e (5) melhoria e incentivos financeiros.

Diversos trabalhos acadêmicos publicados recentemente relatam a adoção, em suas várias etapas de amadurecimento, dos conceitos básicos do sistema de produção enxuta (SPE) pelas indústrias do ramo automotivo. A adoção do SPE teve origem nas grandes montadoras, espalhando-se pelas empresas forne- cedoras, em grande parte por orientação das próprias montadoras, que possuem liderança nas cadeias de suprimento do setor automotivo, influenciando as ações de todos os demais envolvidos. Em uma pesquisa com 68 empresas brasileiras que usam a manufatura enxuta e fazem negócios no Brasil, Moori, Pescarmona e Kimura (2013) analisam a relação entre a gestão de manufatura enxuta, habilidades competitivas e desempenho de negócios. Os resultados mostram uma relação positiva entre a manufatura enxuta e o desempenho dos negócios. Em uma pesquisa para avaliar o nível de aderência das práticas às exigências do SPE, conforme percebido por gerentes de produção de 72 empresas da indústria automotiva, todas com planta no Brasil, Glaser-Segura, Peinado e Graeml (2011) elencam 15 padrões importantes na adoção do SPE: utilização do kanban, apoio da alta direção, redução do tamanho dos lotes de produção, prática dos $5 \mathrm{~S}$, redução do tempo de setup, desenvolvimento de fornecedores, comunicação ou contato com a equipe, informações de processo, controle estatístico de processo, formas de incentivos aos funcionários, custo $A B C$, relacionamentos de longo prazo com fornecedores, comunicação ou contato com os clientes, utilização do ERP e desenvolvimento simplificado de novos produtos. A pesquisa conclui que as condições oferecidas pelas empresas pesquisadas ainda não são completamente favoráveis à implantação plena do SPE. A principal lacuna consiste em deficiências na comunicação e nas formas de abastecimento, tanto internamente como envolvendo fornecedores externos.

Alves, Nogueira e Bento (2011) analisam as estratégias de produção de seis montadoras de motores para automóveis instaladas no Brasil, em uma pesquisa realizada por meio de entrevistas com os principais responsáveis pela unidade produtora. Os autores levantam suas principais ações relativas à operação produtiva, que estão descritas no Quadro 1.

Como se pode observar no Quadro 1, a implementação de um sistema de gestão baseado em lean manufacturing aparece, de maneira declarada, como principal movimento estratégico de produção em duas das seis montadoras de motores estudadas, fato que mostra o interesse na adoção do SPE pelas montadoras.

Em um trabalho sobre práticas de Gestão da Produção utilizadas em grandes indústrias, Saurin, Ribeiro e Marodin (2010) realizam um levantamento a respeito do processo de implantação do SPE em 47 empresas do Brasil e do exterior, sendo 21 delas pertencentes ao ramo automotivo e 20 com planta no Brasil. O levantamento aponta que os principais motivos das empresas para a adoção do SPE foram a necessidade de melhorar a competitividade e a percepção da efetividade do SPE no combate a problemas críticos de produção. Já as principais dificuldades encontradas foram a resistência das pessoas e a dificuldade na adaptação de conceitos e práticas demandados pelo SPE. 
Quadro 1. Principais ações relativas à operação produtiva realizadas pelas montadoras de motores de automóveis

\begin{tabular}{c|l}
\hline Montadora & Principais ações relativas à operação produtiva \\
\hline A & $\begin{array}{l}\text { Melhorias da logística de fornecimento e entrega; aumento do contato com os fornecedores. Melhorias incrementais no } \\
\text { processo de fabricação, visando a melhorar a qualidade e reduzir os custos. }\end{array}$ \\
\hline B & $\begin{array}{l}\text { Redução do grau de verticalização; investimento em máquinas e equipamentos para as novas gerações de motores; } \\
\text { desenvolvimento de novos produtos. }\end{array}$ \\
\hline C & $\begin{array}{l}\text { Terceirização da usinagem de peças de menor importância para o motor; constantes alterações no projeto dos produtos, } \\
\text { ampliando o mix. }\end{array}$ \\
\hline D & $\begin{array}{l}\text { Ampliação da capacidade de produção; aumento no índice de nacionalização de fornecimento; desenvolvimento da área de } \\
\text { projeto do produto no Brasil. }\end{array}$ \\
\hline E & $\begin{array}{l}\text { Implementação de sistema de gestão baseado no lean manufacturing; redução de estoque; efetivação do uso de } \\
\text { ferramentas de gestão para redução de custos e melhoria da qualidade. }\end{array}$ \\
\hline F & $\begin{array}{l}\text { Implementação de sistema de gestão baseado no lean manufacturing; aumento da nacionalização do fornecimento e } \\
\text { melhorias na gestão da cadeia de fornecimento. }\end{array}$ \\
\hline
\end{tabular}

Fonte: Alves et al., (2011, p. 615)

O Quadro 2 apresenta uma listagem em ordem de importância das práticas consideradas prioritárias, no dia a dia do SPE, pelas empresas pesquisadas.

\section{Quadro 2. Práticas consideradas prioritárias para o sistema de produção enxuta}

\begin{tabular}{c|l|c|l}
\hline Posição & Práticas prioritárias & Posição & Práticas prioritárias \\
\hline 1 & Produção puxada & 10 & Lean accounting \\
\hline 2 & Padronização do trabalho & 11 & Logística lean \\
\hline 3 & Gerenciamento visual & 12 & Lean design \\
\hline 4 & Controle de qualidade/zero defeito & 13 & Flexibilização da mão de obra/multifunção \\
\hline 5 & Mapeamento de fluxo de valor & 14 & Produção enxuta \\
\hline 6 & Kaizen e solução de problemas & 15 & Autonomação \\
\hline 8 & Troca rápida de ferramentas & 16 & Lean office \\
\hline 9 & Manutenção produtiva total & 17 & Lean service \\
\hline
\end{tabular}

Fonte: Adaptado de Saurin et al., (2010, p. 839)

Silva et al., (2010) apresentam uma iniciativa de integrar as metodologias da manufatura enxuta e seis sigma na busca de um melhor desempenho operacional em uma unidade fabril em São Paulo de uma empresa multinacional fabricante de autopeças, líder do segmento e fornecedora das montadoras de automóveis. Segundo os autores, a integração das duas metodologias contribuiu para o alcance de expressivos ganhos, tanto em produtividade como em qualidade.

Em estudo de caso, Saurin e Ferreira (2008) fazem uma avaliação qualitativa da implantação de práticas do SPE em uma grande montadora de máquinas agrícolas, que adota o SPE desde 2001. O Quadro 3 apresenta as notas atribuídas pelos pesquisadores ao desempenho da organização estudada relati- vamente às principais práticas da produção enxuta, que foram avaliadas com base em várias fontes de evidências: observação direta, entrevistas com gerentes, supervisores e operadores e análise de documentos.

Com base em uma revisão bibliográfica sobre a manufatura enxuta de 82 artigos encontrados nos mais importantes periódicos nacionais e internacionais na área de Gestão de Operações, Godinho e Fernandes (2004) propõem um sistema de classificação, envolvendo nove princípios com 23 capacitadores (tecnologias, metodologias e ferramentas) que representam a forma de atingir um determinado princípio. 0 Quadro 4 lista os princípios e seus capacitadores, conforme desenvolvidos pelos autores. 
Quadro 3. Notas atribuídas às práticas enxutas avaliadas

\begin{tabular}{l|c|l|l}
\hline Práticas prioritárias & Nota & Práticas prioritárias & Nota \\
\hline Troca rápida de ferramentas & 10,0 & Melhoria contínua & 7,5 \\
\hline Balanceamento da produção & 8,8 & Flexibilização da mão de obra & 6,7 \\
\hline Nivelamento da produção & 8,8 & Manutenção produtiva total & 6,4 \\
\hline Produção puxada e fluxo contínuo & 8,3 & Integração da cadeia de fornecedores & 6,3 \\
\hline Mapeamento de fluxo de valor & 7,5 & Operaçães padronizadas & 6,0 \\
\hline Gerenciamento visual & 7,5 & Controle da qualidade/zero defeito & 5,7 \\
\hline
\end{tabular}

Fonte: Adaptado de Saurin e Ferreira (2008, p. 453)

\section{Quadro 4. Lista de princípios e capacitadores da produção enxuta}

\begin{tabular}{|c|c|}
\hline Princípios & $\begin{array}{l}\text { Capacitadores } \\
\text { (tecnologias, metodologias e ferramentas) }\end{array}$ \\
\hline $\begin{array}{l}\text { Determinação de valor para o cliente, } \\
\text { identificando cadeia de valor e eliminando } \\
\text { desperdícios }\end{array}$ & $\begin{array}{l}\text { Mapeamento do fluxo de valor. Melhoria na relação cliente-fornecedor/redução do número } \\
\text { de fornecedores. Recebimento/fornecimento just-in-time. }\end{array}$ \\
\hline Trabalho em fluxo/simplificação do fluxo & $\begin{array}{l}\text { Tecnologia de grupo. Trabalho em fluxo contínuo (one piece flow)/redução do tamanho de } \\
\text { lote. Trabalho de acordo com o takt time/produção sincronizada. Manutenção produtiva total } \\
\text { (TPM). }\end{array}$ \\
\hline Produção puxada/just-in-time & Recebimento/fornecimento just-in-time. Kanban. Redução do tempo de set up. \\
\hline Busca da perfeição & Kaizen. \\
\hline Autonomação/qualidade seis sigma & Ferramentas de controle da qualidade. Zero defeito. Ferramentas poka yoke. \\
\hline Limpeza, ordem e segurança & $5 \mathrm{~S}$. \\
\hline $\begin{array}{l}\text { Desenvolvimento e capacitação de recursos } \\
\text { humanos }\end{array}$ & $\begin{array}{l}\text { Empowerment. Trabalho em equipes. Comprometimento dos funcionários e da alta gerência. } \\
\text { Trabalhador multi-habilitado/ rodízio de funções. Treinamento de pessoal. }\end{array}$ \\
\hline Gerenciamento visual & Medidas de performance/balanced scorecard. Gráficos de controle visual. \\
\hline $\begin{array}{l}\text { Adaptação de outras áreas da empresa ao } \\
\text { pensamento enxuto }\end{array}$ & Modificação de estrutura financeira/custos. Ferramentas para projeto enxuto (DFMA etc.). \\
\hline
\end{tabular}

Fonte: Godinho e Fernandes (2004, p. 4)

A pesquisa realizada por Godinho e Fernandes (2004) conclui que os temas mais abordados em estudos acadêmicos em relação aos princípios enxutos são: produção puxada/just-in-time, trabalho em fluxo/simplificação do fluxo e desenvolvimento e capacitação de recursos humanos. Os temas menos estudados são gerenciamento visual e ordem, limpeza e segurança. Em relação aos capacitadores enxutos, os temas mais abordados são: o trabalho em equipe, o kanban e a tecnologia de grupo, enquanto a utilização de medidas de performance enxutas e gráficos de controle visual foram os capacitadores menos enfatizados na literatura.

Como foi possivel observar, esse breve referencial teórico envolvendo pesquisas científicas sobre práticas de Gestão de Operações em empresas do ramo automotivo no Brasil aponta, de maneira genérica, para temas que englobam a gestão ca- deia de suprimentos, gestão de projetos, estratégias de produção e diversas variantes do sistema de produção enxuta. A abordagem desses temas, porém, resulta da escolha prévia dos pesquisadores, ao definirem seus objetivos e objetos de pesquisa. Como o presente estudo objetiva capturar temáticas da Gestão de Operações valorizadas pelas empresas industriais, e não pelos pesquisadores, na próxima seção, são descritos os procedimentos definidos e adotados para identificá-las.

\section{PROCEDIMENTOS METODOLÓGICOS}

Nesta pesquisa, buscou-se levantar a importância prática dos diversos temas da Gestão de Operações nos processos produtivos adotados pelas empresas nacionais de manufatura in- 
dustrial. Isso foi feito utilizando-se o mapeamento consolidado de temas em Gestão de Operações mais frequentemente estimulados pelos periódicos e eventos da área, elaborado por Peinado e Graeml (2013), como base para a classificação das práticas adotadas por um conjunto de empresas montadoras do setor automotivo.

Para tal, foram realizadas inicialmente entrevistas semidirigidas com os executivos diretamente responsáveis pelo sis- tema de produção adotado por quatro grandes montadoras do setor automotivo. 0 objetivo era levantar informações sobre 0 sistema de produção adotado pelas empresas pesquisadas, partindo-se do pressuposto de que sua análise minuciosa permitiria revelar os temas em Gestão de Operações mais valorizados na prática diária daquelas organizações. 0 Quadro 5 caracteriza as empresas estudadas, sem identificá-las, pois não se obteve autorização expressa para isso.

Quadro 5. Caracterização das empresas estudadas

\begin{tabular}{l|l|c|c|c}
\hline \multirow{2}{*}{ Empresa } & \multirow{2}{*}{ Descrição da planta pesquisada } & \multicolumn{2}{|l}{ Participação no mercado nacional (2013) } \\
\cline { 3 - 5 } & & Automóveis (\%) & Comerciais leves (\%) & Caminhões e ônibus (\%) \\
\hline A & Montadora de veículos de transporte comercial & - & - & 9,7 \\
\hline B & Montadora de veículos de passeio & 23,5 & 15,4 & - \\
\hline C & Montadora de veículos de passeio & 6,3 & 14,2 & - \\
\hline D & Montadora de motores de veículos de passeio & 21,0 & 23,7 & - \\
\hline
\end{tabular}

Fonte: Anfavea (2014, p. 124)

A amostra formada por essas quatro empresas justificase pela facilidade de contato para a realização das entrevistas, uma vez que todas as empresas possuem planta na região metropolitana de Curitiba, e por se acreditar que empresas montadoras do ramo automotivo têm seu processo de Gestão de Operações bastante amadurecido, comparativamente a outras empresas industriais, em decorrência da tradição e competitividade do setor, que determina fortes exigências de desempenho no dia a dia e adequação a várias normativas de qualidade. Além disso, as empresas montadoras do ramo automotivo, segundo dados de 2012, disponibilizados pela Associação Nacional dos Fabricantes de Veículos Automotores [Anfavea] (2014), representam $18,7 \%$ do Produto Interno Bruto (PIB) brasileiro.

As entrevistas individuais semidirigidas foram realizadas pessoalmente com indivíduos considerados chave na implantação, manutenção e/ou operacionalização do sistema de produção adotado pelas organizações. Elas foram essenciais para se obter acesso aos documentos utilizados como diretrizes para os sistemas de produção implantados pelas empresas pesquisadas.

Em busca de uma forma para mensurar a atenção dispensada pela indústria aos diversos temas tratados pela Gestão de Operações, decidiu-se pela análise de conteúdo das fontes documentais, representadas por esses documentos-base dos sistemas de produção. Segundo Bardin (2009), análise de conteúdo é o conjunto de técnicas de análise das comunicações, adotando procedimentos objetivos (quantitativos ou não) de tratamento do conteúdo das mensagens que possibilitem realizar inferências sobre variáveis relacionadas às mensagens analisadas. Essa técnica pode ser utilizada para analisar materiais escritos, desmembrando-os em unidades significativas, adotando-se critérios bem definidos e cuidadosamente aplicados (McDaniel, 2004). Dessa forma, a análise de conteúdo realizada permitiu que os temas sobre Gestão de Operações praticados nas organizações pudessem ser extraídos dos materiais escritos coletados. A frequência relativa de aparecimentos de cada tema (unidade significativa) foi utilizada como forma de mensuração da importância atribuída ao tema.

\section{Seleção das fontes documentais da pesquisa}

As entrevistas semidirigidas permitiram identificar que cada uma das quatro empresas pesquisadas reúne e formaliza o sistema de produção adotado em um documento formalmente estruturado, que traduz as diretrizes básicas adotadas, tais como missão, valores, princípios e ferramentas da Gestão de Operações que a organização valoriza. A adoção plena na prática dos preceitos desses documentos foi externada por todos os entrevistados, em declarações como: "O sistema de produção [referindo-se ao documento] é uma verdadeira cartilha que norteia nossas ações nas linhas de produção", ou então: "Constantemente são oferecidos cursos de aprimoramento e divulgação do nosso sistema de produção contido neste documento", ou ainda: "Todos os funcionários têm conhecimento do nosso sistema de produção".

Foram utilizados quatro documentos, um para cada organização, como fonte de dados para esse levantamento baseado em análise de conteúdo, os quais são apresentados no Quadro 6. 
Quadro 6. Fontes documentais utilizadas na pesquisa

\begin{tabular}{c|c|c}
\hline Empresa & Fonte documental utilizada & Número de páginas \\
\hline A & VPS booklet & 68 \\
\hline B & Manual SPVW & 176 \\
\hline C & SPR management book & 49 \\
\hline D & $\begin{array}{c}\text { Manual WCM (World Class } \\
\text { Manufacturing) }\end{array}$ & 289 \\
\hline
\end{tabular}

Fonte: Documentos indicados e fornecidos pelos entrevistados

Os entrevistados também informaram que o sistema de produção adotado em suas organizações é de abrangência corporativa, o que quer dizer que todas as plantas industriais que compõem cada uma das empresas estudadas adotam, em nível mundial, as mesmas práticas de Gestão de Operações descritas e formalizadas nesses documentos. Esse nível de abrangência representa uma importante justificativa para o uso desses documentos como objeto de análise para a realização da pesquisa ora proposta.

\section{Procedimentos de tratamento e análise dos dados}

O conteúdo das fontes documentais descritas no Quadro 6 foi analisado com o auxílio do software NVivo versão 9. Os quatro arquivos digitais dos documentos foram inseridos como arquivos de categoria fonte no NVivo. Foram criados 45 nós (recipientes digitais que permitem reunir materiais relacionados com a finalidade de auxiliar a procura de padrões e ideias), um nó para cada um dos 45 temas propostos no mapeamento consolidado de temas em Gestão de Operações elaborado por Peinado e Graeml (2013) com base na perspectiva da oferta de espaço editorial pelas revistas e congressos da área.

Após a inserção das quatro fontes documentais e a criação dos nós, procedeu-se a uma minuciosa análise de conteúdo das fontes por meio da criação de referências. Uma a uma, cada referência foi criada à medida que um trecho do texto (frase, sentença, parte de parágrafo ou parágrafo inteiro) era analisado e seu conteúdo, associado a um ou mais dos 45 nós. Por exemplo, o trecho de texto: “Estratificação/Diagrama de Pareto. A estratificação é um instrumento que permite analisar os dados disponíveis explodindo até o último nível possível" foi associado ao nó Gerenciamento da qualidade, uma vez que as palavras estratificação e diagrama de Pareto são duas conhecidas ferramentas da qualidade. Em várias ocasiões, um mesmo trecho de texto pôde ser associado a mais de um nó. Por exemplo, o texto: “Em um estabelecimento World Class, a melhoria contínua aplica-se através da abordagem para solução de problemas na lógica PDCA (Planejar, Fazer, Verificar, Agir - Planejar, Intervir, Controlar os resultados, Expandir as atividades para áreas semelhantes) abrangendo todas as pessoas que fazem parte da organização" foi associado aos nós: manufatura enxuta (World Class é um sistema de manufatura enxuta), gestão da qualidade total (o texto cita melhorias contínuas e o envolvimento de todas as pessoas da organização) e gestão da qualidade (ferramenta PDCA).

\section{ANÁLISE DOS RESULTADOS}

O procedimento de identificação e classificação dos temas abordados pelos quatro documentos selecionados para análise, que tratavam do sistema de produção adotado pelas quatro montadoras, pretendeu levantar o valor prático atribuído a cada um deles pelas organizações estudadas. Para isso, foi contado o número de vezes que cada tema, ou tópico a ele relacionado, foi mencionado nos documentos analisados. A Tabela 1 apresenta a distribuição do resultado dessa análise.

A Tabela 1 mostra a quantidade de menções a temas encontradas na análise de conteúdo realizada individualmente por empresa. A última coluna apresenta o cômputo total das quatro empresas. Levando-se em consideração a diferença dos totais de referências entre as quatro empresas, apresentada na última linha da Tabela 1, o que pode ter ocorrido devido à diferença de densidade dos documentos analisados (ver Quadro 6), os resultados foram relativizados em forma percentual por meio do quociente entre a quantidade de menções ao tema individual e a quantidade total de menções por organização. Os resultados relativizados são mostrados como um percentual, entre parênteses.

Os dados consolidados na última coluna da Tabela 1 evidenciaram seis assuntos mais comuns, com $62,1 \%$ do total das menções, na prática da Gestão de Operações pelas corporações estudadas; dois deles sobressaem, sendo responsáveis, juntos, por 36,1\% das menções catalogadas na análise de conteúdo. São eles: Gestão da qualidade (com 20,3\%) e Sistema de produção enxuta (com 15,8\%). Cabe esclarecer que Gestão da qualidade foi a única categoria agregada, em que se optou por somar o número de menções referentes a Gerenciamento da qualidade e Gestão da qualidade total. Isso foi possível porque os autores, ao realizarem a categorização das menções a essas duas temáticas, tinham, nesse caso específico, tomado o cuidado de não realizar sombreamentos, ou seja, o que havia sido incluído em uma das subcategorias não havia entrado na outra. A subcategorização, nesse caso, já havia se demonstrado um pouco problemática, apesar da tentativa de se enquadrar o que era mais pontual na subcategoria Gerenciamento da qualidade e o que era mais sistêmico na subcategoria Gestão da qualidade total, tendo sido mantida apenas em observância às categorias temáticas propostas no mapeamento de temáticas adotado no estudo (Peinado \& Graeml, 2013). 
TABELA 1. Número de menções a temas nas fontes documentais de pesquisa

(Continua)

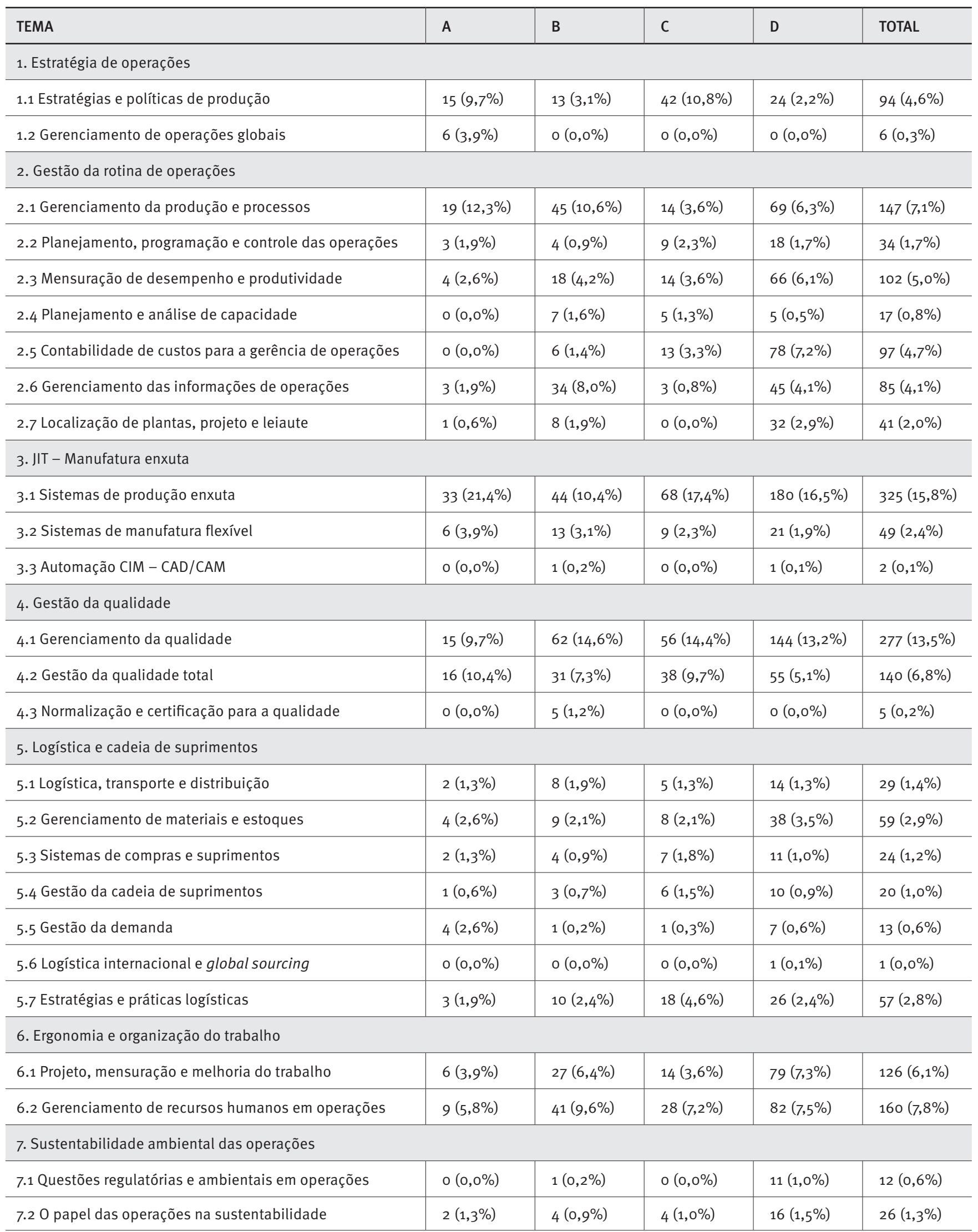


TABELA 1. Número de menções a temas nas fontes documentais de pesquisa

(Conclusão)

\begin{tabular}{|c|c|c|c|c|c|}
\hline TEMA & $A$ & B & $\mathrm{C}$ & D & TOTAL \\
\hline 7.3 Estratégia de negócios sustentáveis & $0(0,0 \%)$ & $2(0,5 \%)$ & $2(0,5 \%)$ & $8(0,7 \%)$ & $12(0,6 \%)$ \\
\hline \multicolumn{6}{|l|}{ 8. Gestão de projetos e desenvolvimento de produtos } \\
\hline 8.2 Projeto e desenvolvimento de produtos & $0(0,0 \%)$ & $7(1,6 \%)$ & $7(1,8 \%)$ & $3(0,3 \%)$ & $17(0,8 \%)$ \\
\hline 8.3 Projeto de manufatura & $0(0,0 \%)$ & $5(1,2 \%)$ & $7(1,8 \%)$ & $10(0,9 \%)$ & $22(1,1 \%)$ \\
\hline \multicolumn{6}{|l|}{ 9. Gestão da inovação e tecnologia } \\
\hline 9.1 Gerência de tecnologia para operações & $0(0,0 \%)$ & $1(0,2 \%)$ & $1(0,3 \%)$ & $0(0,0 \%)$ & $2(0,1 \%)$ \\
\hline 9.4E-business e operações & $0(0,0 \%)$ & $0(0,0 \%)$ & $0(0,0 \%)$ & $0(0,0 \%)$ & $0(0,0 \%)$ \\
\hline 9.5 Inovação tecnológica & $0(0,0 \%)$ & $0(0,0 \%)$ & $1(0,3 \%)$ & $0(0,0 \%)$ & $1(0,0 \%)$ \\
\hline \multicolumn{6}{|l|}{ 10. Operações de serviços } \\
\hline 10.1 Estratégias de operações de serviços & $0(0,0 \%)$ & $1(0,2 \%)$ & $0(0,0 \%)$ & $0(0,0 \%)$ & $1(0,0 \%)$ \\
\hline 10.2 Gerência de operações em organizações de serviços & $0(0,0 \%)$ & $1(0,2 \%)$ & $0(0,0 \%)$ & $0(0,0 \%)$ & $1(0,0 \%)$ \\
\hline 10.3 Produção enxuta em serviços & $0(0,0 \%)$ & $0(0,0 \%)$ & $0(0,0 \%)$ & $0(0,0 \%)$ & $0(0,0 \%)$ \\
\hline 10.9 Gestão da inovação e tecnologia em serviços & $0(0,0 \%)$ & $0(0,0 \%)$ & $0(0,0 \%)$ & $0(0,0 \%)$ & $0(0,0 \%)$ \\
\hline Total de referências & 154 & 425 & 390 & 1088 & 2057 \\
\hline
\end{tabular}

Os outros quatro temas que se destacaram foram: Gerenciamento de recursos humanos em operações (com 7,8\%), Gerência de operações (com 7,1\%), Projeto, mensuração e melhoria do trabalho (com 6,1\%), e Mensuração do desempenho e produtividade (com 5,0\%). 0 Quadro 7 apresenta a relação desses seis temas e as palavras ou expressões encontradas nos documentos analisados que foram consideradas como fazendo menção a cada um deles, na análise de conteúdo realizada.

Percebe-se ainda, ao se analisarem os dados expostos na Tabela 1, que todos os seis temas (mostrados no Quadro 7) resultaram como os mais mencionados nos documentos analisados para todas as quatro empresas estudadas. As porcentagens das menções por empresa para cada um desses temas não apresentaram diferença que mereça destaque, exceto pelo tema Gerenciamento da produção e processos, que foi menos mencionado no sistema de produção da empresa C.

Os seis temas que despontaram como os mais mencionados nas fontes documentais de pesquisa evidenciam também elevado nível de aderência às exigências do SPE. 0 Quadro 8 apresenta o relacionamento entre os temas mais referenciados na análise de conteúdo e a relação de capacitadores da produção enxuta, proposta por Godinho e Fernandes (2004) no Quadro 4, apresentado no referencial teórico. 


\section{Quadro 7. Relação das palavras ou expressões encontradas nas fontes documentais de pesquisa que foram associadas aos respectivos temas de Gestão de Operações na análise de conteúdo}

4 - Gestão da qualidade: definição e medida da qualidade; ferramentas da qualidade; controle estatístico de processo; controle estatístico da qualidade; evolução da gestão da qualidade; método de análise e solução de problemas; métodos específicos de gestão da qualidade; ferramentas da qualidade; inspeção por amostragem; organização do controle da qualidade; capabilidade de processos; prevenção e recuperação de falhas; inspeção e ensaios; ciclo PDCA; controle da qualidade; programa 5S; custo da qualidade; círculos de controle da qualidade (CCQ); melhoria contínua; benchmarking; programas gerenciais da qualidade; administração da qualidade; auditoria geral; PDCA abrangendo todas as pessoas que fazem parte da organização; identificar as causas dos desvios e removê-las definitivamente; inovar por meio da introdução de um novo padrão; seis sigmas; quick kaizen; TPM; poka yoke; zero defeito; qualidade assegurada do fornecedor; garantia da qualidade; total quality da confiabilidade.

3.1 - Sistema de produção enxuta: lean production; zero incidente; estabelecer o World Class Manufacturing (WCM); envolver todas as pessoas; cost deployment; eliminação de desperdícios; operações que não agregam valor; priorização de projetos de redução de desperdícios; análise custo $\mathrm{x}$ benefício; identificação sistemática dos desperdícios; melhorias contínuas; desempenho WCM, classificação dos tipos de perdas; zero estoque; zero parada; custos das perdas, pilares técnicos WCM; one piece flow; 18 perdas da logística; sete desperdícios; just-in-time; takt-time; estabilização de todos os processos da empresa, produção pull; redução do lead time; redução dos estoques; kanban; mapa de fluxo de valor, TPM.

6.2 - Gerenciamento de recursos humanos em operações: people deployment; sensibilização das pessoas; cultura de segurança; treinamento de formação; elaboração de manuais ilustrativos; reuniões em nível de fábrica; programa de higiene (dieta, fumo, peso etc.); campanhas de comunicação e desenvolvimento; recursos humanos e qualidade; perdas por greve e absenteísmo; competências pessoais; identificar necessidades de treinamentos; proposição das pessoas que trabalham na linha; erros humanos; treinamentos on-the-job; estratégias de desenvolvimento de pessoas, centros de treinamento na fábrica; coaching; habilidades dos operadores; respeito mútuo; ética; plano de carreira; gerenciamento sereno e entusiástico; envolvimento de todos os empregados; implementação das boas ideias; matriz de qualificação do funcionário; plano de integração, multifunção.

2.1 - Gerenciamento da produção e processos: roteiro de fabricação; normativas; responsável pela administração e controle, atividades repetitivas de manufatura; estação de trabalho; estratégia kaizen para melhoria do processo; controles visuais; reuniões para discutir erros recorrentes; elaboração dos padrões de produção; auditorias constantes; outputs dos processos produtivos; cronoanálise; estudo de tempos e movimentos; monitoramento constante; procedimentos operacionais; sistemas MTM; balanceamento de linhas de montagem; takt time; diagramas de movimentação; folhas de instrução de trabalho; trabalho padronizado.

6.1 - Projeto, mensuração e melhoria do trabalho: eliminação de acidentes; segurança do posto de trabalho; 16 famílias de riscos; melhoria do sistema pessoa/máquina; tipos de acidentes; padrões de segurança; condições básicas do posto de trabalho e oficina; excesso de espaço de movimentação; remoção das fontes de sujeira e de pó; escolha do leiaute mais adequado; projeto de workplace organization; movimentação mínima dos materiais; fábrica luminosa, limpa e fluida; organização do local de trabalho; estação de trabalho ideal; processo robusto; ergonomia; segurança da posição e bem-estar do indivíduo; análise ergonômica das posições de trabalho; MURI, MURA, MUDA; gráfico de spaghetti; redução de tempo de atividades de valor não agregado; housekeeping; melhoria do ambiente de trabalho; transparência do processo de trabalho; satisfação dos funcionários; ambientes de trabalho seguros e agradáveis.

2.3 - Mensuração do desempenho e produtividade: controles visuais; controle rigoroso; coleta e teste de informações; auditorias frequentes; acompanhamento dos KPIs; valores nominais, tolerâncias, avaliar funções e criar controles necessários; mapa das quebras; estabelecer padrões claros; efetuar um rigoroso controle autônomo; lista de anomalias identificadas, designação de cada responsável; nível de performance por estação de trabalho; reuniões diárias; performance das equipes; plano de ação detalhado; controles mais simples. 
Quadro 8. Comparação entre os seistemas mais mencionados e os capacitadores da produção enxuta propostos por Godinho e Fernandes (2004)

\begin{tabular}{l|l}
\hline $\begin{array}{l}\text { Seis temas mais } \\
\text { referenciados nos } \\
\text { sistemas de produção }\end{array}$ & $\begin{array}{l}\text { Temas capacitadores da produção } \\
\text { enxuta }\end{array}$ \\
\hline Gerência da qualidade & $\begin{array}{l}\text { Ferramentas de controle da qualidade. } 5 \text { S. } \\
\text { Ferramentas poka yoke. Kaizen. Zero defeito. }\end{array}$ \\
\hline & $\begin{array}{l}\text { Mapeamento do fluxo de valor. } \\
\text { Recebimento e fornecimento just-in- } \\
\text { time. Trabalho em fluxo contínuo (one } \\
\text { piece flow). Redução do tamanho de } \\
\text { lote. Redução do tempo de setup. } \\
\text { Manutenção produtiva total (TPM). } \\
\text { Kistemas de produçãon. Ferramentas para projeto enxuto } \\
\text { (DFMA etc.). }\end{array}$ \\
\hline $\begin{array}{l}\text { Gerenciamento de } \\
\text { recursos humanos em } \\
\text { operações }\end{array}$ & $\begin{array}{l}\text { Trabalhador multi-habilitado. Rodízio } \\
\text { de funções. Treinamento de pessoal. } \\
\text { Comprometimento dos funcionários e da } \\
\text { alta gerência. Empowerment. Trabalho } \\
\text { em equipes. }\end{array}$ \\
\hline $\begin{array}{l}\text { Gerência da produção } \\
\text { e processos }\end{array}$ & $\begin{array}{l}\text { Trabalhar de acordo com o takt time. } \\
\text { Produção sincronizada. }\end{array}$ \\
\hline $\begin{array}{l}\text { Projeto, mensuração e } \\
\text { melhoria do trabalho }\end{array}$ & $\begin{array}{l}\text { Medidas de performance. Balanced } \\
\text { scorecard. }\end{array}$ \\
\hline $\begin{array}{l}\text { Mensuração do } \\
\text { produtividade }\end{array}$ & \begin{tabular}{l} 
Grácos de controle visuais. \\
\hline
\end{tabular} \\
\hline
\end{tabular}

Como pode ser observado no Quadro 8, os temas mais mencionados na análise de conteúdo das fontes documentais de pesquisa, mostrados na primeira coluna, incorporam vários capacitadores da produção enxuta, mostrados na segunda coluna, conforme proposto por Godinho e Fernandes (2004). Esses padrões apontam que a adoção dos conceitos básicos do SPE encontra-se bastante amadurecida nas montadoras de veículos estudadas. Isso alinha-se com o exposto, no referencial teórico, por pesquisadores como Glaser-Segura et al., (2011), Alves et al., (2011), Saurin et al., (2010), Silva et al., (2010) e Saurin e Ferreira (2008), que avaliam as formas de aderência às exigências do SPE em empresas da indústria automotiva.

0 tema Gerenciamento de recursos humanos em operações aparece em terceiro lugar no ranking dos temas da Gestão de Operações mais mencionados nas fontes documentais de pesquisa. Uma análise mais detalhada dos assuntos que remetem ao tema pode proporcionar uma pista quanto ao tipo de preocupação, dispensado pelas empresas, para com as pessoas nas operações produtivas. Os 25 assuntos da análise de conteúdo que direcionaram ao tema Gerenciamento de recursos humanos em operações, apresentados no Quadro 7, podem ser resumidos em quatro tópicos principais: saúde, segurança, qualificação e comprometimento do trabalhador. Os assuntos foram, então, quantificados pelo número de menções nos documentos do sistema de produção das organizações pesquisadas. A Tabela 2 apresenta os resultados obtidos.

\section{TABELA 2. Número de menções aos assuntos que se referem à preocupação com as pessoas nas operações produtivas encontradas nas fontes documentais de pesquisa}

\begin{tabular}{|c|c|c|c|c|c|}
\hline Preocupação com as pessoas nas operações produtivas & A & B & C & D & TOTAL \\
\hline Segurança & $\begin{array}{l}1 \\
(11,1 \%)\end{array}$ & $\begin{array}{l}3 \\
(7,3 \%)\end{array}$ & $\begin{array}{l}0 \\
(0,0 \%)\end{array}$ & $\begin{array}{l}15 \\
(18,3 \%)\end{array}$ & $\begin{array}{l}19 \\
(11,9 \%)\end{array}$ \\
\hline Comprometimento & $\begin{array}{l}5 \\
(55,6 \%)\end{array}$ & $\begin{array}{l}12 \\
(29,3 \%)\end{array}$ & $\begin{array}{l}12 \\
(42,9 \%)\end{array}$ & $\begin{array}{l}22 \\
(26,8 \%)\end{array}$ & $\begin{array}{l}51 \\
(31,9 \%)\end{array}$ \\
\hline Total & $\begin{array}{l}9 \\
(5,6 \%)\end{array}$ & $\begin{array}{l}41 \\
(25,6 \%)\end{array}$ & $\begin{array}{l}28 \\
(17,5 \%)\end{array}$ & $\begin{array}{l}82 \\
(51,3 \%)\end{array}$ & $\begin{array}{l}160 \\
(100 \%)\end{array}$ \\
\hline
\end{tabular}

Os resultados apresentados na Tabela 2 mostram maior número de menções para ações que resultem no aprimoramento da qualificação e na obtenção do comprometimento do trabalhador. Esse resultado alinha-se ao mencionado, no referencial teórico, por Gonzalez e Martins (2011) e Jabbour et al., (2012) sobre a necessidade das organizações estimularem a aprendizagem (qualificação) e a cooperação (comprometimento) entre seus funcionários para aumentar o desempenho operacional. Salerno (2004) e Antunes (2003) também mencionam a adoção no Brasil, a partir dos anos 1990, de maior 
participação dos trabalhadores nas decisões do chão de fábrica e de métodos participativos dos trabalhadores aos planos das empresas. 0 fato de a preocupação com a saúde e segurança do trabalhador não ser mencionada por algumas empresas não quer dizer que não exista, e talvez signifique até o oposto: pode ser algo tão óbvio e incorporado à cultura, estrutura e processos que não precisa ser destacado nos documentos pesquisados.

De modo mais pontual, quanto à falta de uniformidade na menção dos temas entre as empresas, apenas dois temas destacaram-se. Em primeiro lugar, o resultado da análise de conteúdo dos documentos mostrou haver mais menções ao tema Estratégias de operações pelas empresas C e A, com respectivamente $10,8 \%$ e $9,7 \%$ das menções, do que nas empresas $B$ e $D$, com respectivamente $3,1 \%$ e $2,2 \%$ das referências. Em segundo lugar, constatou-se um percentual de 8,0\% de menções ao tema Gerenciamento das informações de operações pela empresa $\mathrm{B}$, contrapondo-se aos $4,1 \%, 0,8 \%$ e $1,9 \%$ das empresas D, C e A, respectivamente. Dessa forma, a análise dos resultados da Tabela 1, de maneira geral, mostrou que existe uniformidade nas práticas de Gestão de Operações adotadas pelas grandes corporações da indústria automotiva.

Prosseguindo a análise dos resultados, do lado oposto, alguns temas da Gestão de Operações não foram mencionados ou raramente o foram nos documentos que estruturam os sistemas de produção das empresas pesquisadas. Nessa situação, dois temas merecem destaque: Automação CIM - CAD/CAM, com $0,1 \%$ das menções, e Normalização e certificação para a qualidade, com o,2\% das menções. Assim como já destacado com relação à Saúde e segurança do trabalhador, isso não quer dizer que, necessariamente, essas temáticas não sejam importantes, apenas significa que não são mencionadas nos documentos que norteiam os sistemas de produção das empresas pesquisadas.

Praticamente nenhum dos temas de 10.1 a 10.9, referentes às operações de serviços, foi mencionado nas fontes documentais de pesquisa. Esse resultado já podia ser esperado, em função de a pesquisa envolver operações industriais, apenas.

Apesar da importância do Gerenciamento da cadeia de suprimentos destacada por vários autores, tais como Vanalle e Salles (2011), Guarnieri e Hatakeyama (2010) e Pires e Sacomano (2010), nenhum dos temas de 5.1 a 5.7, referentes à Logística e cadeia de suprimentos, apresentou frequência de menções expressiva na pesquisa. Isso pode ser consequência de os documentos estudados se restringirem aos processos produtivos internos, enquanto as práticas logísticas envolvendo fornecedores externos são descritas por outros documentos e normas mais específicas.

\section{CONCLUSÃO}

Partindo-se do objetivo de verificar a percepção da importância atribuída aos temas da Gestão de Operações pelos seus praticantes (pratictioners), foi possível chegar a algumas contribuições interessantes para a academia e para as empresas. A primeira delas consistiu na revelação empírica de seis temas mais referenciados nos conteúdos dos principais documentos que direcionam os sistemas de produção adotados pelas empresas estudadas: (1) gestão da qualidade, (2) sistema de produção enxuta, (3) gerenciamento de recursos humanos em operações, (4) gerenciamento da produção e processos; (5) projeto, mensuração e melhoria do trabalho; e (6) mensuração do desempenho e produtividade.

Foi possível constatar, também, que esses seis temas que despontaram como os mais mencionados nas fontes documentais da pesquisa evidenciam elevado nível de aderência às exigências do SPE.

Os resultados mostram, ainda, a preocupação com as pessoas nas operações produtivas, sendo maior o número de menções referentes a ações que resultam no aprimoramento da qualificação e na obtenção do comprometimento do trabalhador.

Apesar dos resultados obtidos, este estudo apresenta algumas limitações que reduzem o alcance das suas conclusões. A principal limitação, na avaliação dos autores, é a existência de alguma subjetividade na interpretação dos conteúdos dos documentos analisados, inerente ao processo de classificação dos temas na análise de conteúdo. Uma segunda limitação refere-se ao fato de a pesquisa incluir apenas as grandes montadoras de veículos, embora deva-se levar em consideração que tais empresas são impulsionadoras e atuam como padrões de benchmarking nas práticas de Gestão de Operações para muitas outras. Outra limitação a ser destacada é o fato de que uma temática não ser mencionada não significa que não seja utilizada. Um tópico pode, assim, deixar de constar da documentação que serve de diretriz para o seu sistema de produção não por não ser importante, mas porque já está completamente imbricado na cultura organizacional.

Independentemente dos métodos e abordagens adotados para classificar as temáticas relacionadas à Gestão de Operações e dos juízos que se possa fazer com base neles, é importante que iniciativas nesse sentido não deixem de ocorrer. Considera-se que a discussão realizada neste trabalho sobre a importância atribuída aos temas da Gestão de Operações pelos seus praticantes tenha sido relevante não só pelos resultados que se pôde obter, mas por estimular o debate sobre práticas de Gestão de Operações, propiciando uma oportunidade a mais para se refletir sobre o potencial da Gestão de Operações na formação dos administradores do futuro. 


\section{REFERÊNCIAS}

Alves, A. G, Nogueira, E, \& Bento, P. E. G. (2011). Análise das estratégias de produção de seis montadoras de motores para automóveis. Gestão e Produção, 18(3), 603-618.

Antunes, R. (2003). Os caminhos da liofilização organizacional: as formas diferenciadas da reestruturação produtiva no Brasil. Ideias, 10(1), 13-24.

Associação Nacional dos Fabricantes de Veículos Automotores. (2014). Anuário da indústria automobilística brasileira.

Bardin, L. (2009). Análise de conteúdo. Lisboa: Edições 70.

Glaser-Segura, D. A, Peinado, J, \& Graeml, A. R. (2011). Fatores influenciadores do sucesso da adoção da produção enxuta: uma análise da indústria de três países de economia emergente. RAUSP-Revista de Administração da Universidade de São Paulo, 46(4), 423-436.

Godinho, M, \& Fernandes, F. C. F. (2004). Manufatura enxuta: uma revisão que classifica e analisa os trabalhos apontando perspectivas de pesquisas futuras. Gestão e Produção, 11(1), 1-19.

Gonzalez, R. V. D, \& Martins; M. F. (2011). Melhoria contínua e aprendizagem organizacional: múltiplos casos em empresas do setor automobilístico. Gestão e Produção, 18(3), 473-486.

Guarnieri, P, \& Hatakeyama, K. (2010). Formalização da logística de suprimentos: caso das montadoras e fornecedores da indústria automotiva brasileira. Revista Produção, 20(2), 186-199.

Jabbour, C. J. C, Freitas, W. R. S, Teixeira, A. A, \& Jabbour, A. B. L. S. (2012). Gestão de recursos humanos e desempenho operacional: evidências empíricas. Gestão e Produção, 19(2), 347-360.

McDaniel, C, Jr, \& Gates, R. (2004). Pesquisa de marketing. São Paulo: Pioneira Thomson Learning.

Melo, Y. C, \& Pereira, M. C. (2012). Plataforma de aprendizagem para gestão de projetos: dois casos de implementação de projetos de automação para a indústria automobilística. Gestão e Produção, 19(3), 457-470.

Moori, R. G, Pescarmona, A, \& Kimura, H. (2013). Lean manufacturing and business performance in Brazilian firms. Journal of Operations and Supply Chain Management, 6(1), 91-105.
Muniz, J, Jr, Faria, A, Neto, \& Sá, H. S. (2011). Production organization, work organization and knowledge management: a blue collar perspective in an automaker assembly line. Journal of Operations and Supply Chain Management, 4(2), 99-109.

Peinado, J, \& Graeml, A. R. (2013). Mapeamento das temáticas de gestão de operações: uma análise baseada na oferta de espaço editorial pelas revistas e congressos da área. REGE-Revista de Gestão, 20(3), 367-386.

Pires, S. R. I, \& Sacomano, M, Neto. (2010). Características estruturais, relacionais e gerenciais na cadeia de suprimentos de um condomínio industrial na indústria automobilística. Revista Produção, 20(2), 172-185.

Prieto, E, \& Miguel, P. A. C. (2011). Adoção da estratégia modular por empresas do setor automotivo e as implicações relativas à transferência de atividades no desenvolvimento de produto: um estudo de casos múltiplos. Gestão e Produção, 18(2), 425-442.

Rodrigues, E. A, Carnevalli, J. A, \& Miguel, P. A. C. (2012). Uma investigação sobre a relação entre o projeto do produto e produção em uma montadora automotiva e fornecedores de motores que adotam a modularidade. Revista Produção, 22(3), 367-379.

Salerno, M. S. (2004). Da rotinização à flexibilização: ensaio sobre o pensamento crítico brasileiro de organização do trabalho. Gestão \& Produção, 11(1), 21-32.

Saurin, T. A, \& Ferreira, C. F. (2008). Avaliação qualitativa de práticas da produção enxuta: estudo de caso em uma fábrica de máquinas agrícolas. Gestão e Produção, 15(3), 449-462.

Saurin, T. A, Ribeiro, J. L. D, \& Marodin, G. A. (2010). Identificação de oportunidades de pesquisa a partir de um levantamento da implantação da produção enxuta em empresas do Brasil e do exterior. Gestão e Produção, 17(4), 829-841.

Silva, C. E. S, Mello, C. H. P, Siqueira, N. F. G, Godoy, H. A, \& Salgado, E. G. (2010). Aplicação do gerenciamento de riscos no processo de desenvolvimento de produtos nas empresas de autopeças. Revista Produção, 20(2), 200-213

Vanalle, R. M, \& Salles, J. A. A. (2011). Relação entre montadoras e fornecedores: modelos teóricos e estudos de caso na indústria automobilística brasileira. Gestão e Produção, 18(2), 237-250.

Vieira, G. B. B, Pasa, G. S, Borsa, M. B. N. O, Milan, G. S, \& Pandolfo, A. (2011). Materials handling management: a case study. Journal of Operations and Supply Chain Management, 4(2), 19-30. 